\title{
Ruz, Mario Humberto (Coord.), (2012) “El arte del tiempo maya”. Artes de México, núm. 107. MéXICO: Artes de MéXICO y del Mundo.
}

\author{
Jorge Ramón González-Ponciano
}

$\mathrm{D}$ urante más de veinte años, la editorial Artes de México y del Mundo ha publicado volúmenes de extraordinaria factura sobre el patrimonio de los pueblos mesoamericanos. El número 107 de la revista Artes de México, publicado por esta editorial, no es la excepción y en el mismo destaca la alta calidad de las ilustraciones y el sustento histórico y etnográfico provisto por un equipo de especialistas convocado por Mario Humberto Ruz, a iniciativa de Margarita Orellana, para abordar el arte del tiempo entre los mayas. Seis historiadoras, un arqueólogo y el propio Ruz abordan a lo largo de más de cien páginas el papel del conocimiento astronómico en la vida individual, institucional y social de ese pueblo ancestral. Se privilegia el estudio de tres calendarios principales y otras formas de contar el tiempo, que las diversas fuentes aseguran que son de siete a veinte. Lo cierto es que, aunque hubo períodos en los que algunos cayeron en desuso, tales calendarios, como señala Ruz, no estaban destinados solamente a marcar las grandes acciones de los gobernantes, sino que también servían para organizar la vida cotidiana en sus aspectos más concretos, de manera que el interés astronómico no obedeció exclusivamente a preocupaciones religiosas o científicas. Antes bien, era y es indispensable para conocer la sucesión de los ciclos temporales, la recurrencia de los fenómenos atmosféricos y el movimiento de los astros, para organizar las actividades agrícolas, de caza, pesca y recolección, para normar eventos sociales y para dar fe de acontecimientos históricos o incluso míticos.

El vivir todos los días con la doble marcación calendárica maya y cristiana, señala Ruz, mayanizó el devenir occidental; se convirtió la manzana prohibida del Edén perdido en zapote prohibido, como lo establece el Título de los señores de Totonicapán, en donde también el primer caudillo y profeta Balam Quitzé, cual Moisés conduciendo al pueblo hebreo, abrió con su bastón las aguas del océano para permitir el paso de los pueblos mayas. Balam Ak'ab e Iqui Balam lloraron por haber perdido "la rectitud allá en Egipto"; el Espíritu Santo se mezcló con los guardianes de los cerros y los seres del inframundo maya, y al calor de la migración transnacional surgieron narraciones sincréticas de los que viajan a levantar la sombra o el alma de los paisanos muertos en Canadá o Estados Unidos.

José Ramón González Ponciano. Investigador en el Programa de Investigaciones Multidisciplinarias sobre Mesoamérica y el Sureste del Instituto de Investigaciones Antropológicas de la UNAM, México.

Recibida: 10 de enero de 2014. 
Laura Sotelo distingue el tiempo cíclico y el tiempo lineal remitiéndose a Nancy Farris, que en años anteriores se refirió al tiempo cíclico como repetición perpetua de los ritmos diurnos de la naturaleza, con lo cual el pasado se repite hasta el infinito, mientras que el tiempo lineal avanza a través de una cadena irreversible de eventos. De esta manera, en el tiempo cíclico, el pasado es profecía y, en el tiempo lineal, la profecía es más bien prólogo. Sotelo ofrece una rápida caracterización de los calendarios ritual, solar y el de cuenta larga, resaltando la presencia contemporánea de los ajq'ijab o contadores de los días, quienes entre los ixiles y los kichés guatemaltecos continúan con la tradición de utilizar el tzolkin, llamado así por William E. Gates para diferenciarlo del calendario nahuatl conocido como tonalámatl.

La epigrafista e historiadora Maricela Ayala recuerda que Uaxactún inventó un ciclo lunar y examina algunos de los textos epigráficos más tempranos, como las estelas 12 y 13 de Monte Albán, que contienen registros de quinientos años antes de Cristo. Nos muestra, además, el uso de los calendarios y la estrategia de invención de ciclos, como en el caso de Kinich Kan Balam en Palenque, quien al igual que otros dignatarios desarrolló sus propias formas de escribir las fechas de una historia que, como la suya, era considerada sagrada.

Laura Caso Barrera aborda la ardua labor de los intelectuales indígenas que articularon las dos concepciones del tiempo, la cíclica y la lineal, a partir de complicadas correlaciones calendáricas destinadas al doble propósito de cumplir con las fiestas de guardar del santoral cristiano y continuar usando el tzolkin sin levantar sospechas. Caso Barrera recalca el hecho de que durante la etapa colonial fue muy difícil para los eclesiásticos manejar y comprender los calendarios indígenas, y la importancia que calendarios, profecías y augurios tenían para las festividades mayores de los poderes dinásticos y para el bajo pueblo, que los empleaba para resolver sus problemas cotidianos.

Mercedes de la Garza, apoyándose en las investigaciones epigráficas de Guillermo Bernal Romero sobre la historia dinástica de Palenque, dice que entre los mayas el "tiempo sagrado" del mito está entrelazado con el tiempo profano, y que coexisten pasado, presente, futuro. Pero el tiempo del mito es atemporal y está en completa quietud. Según el mito, las deidades hicieron emerger la tierra de las aguas primordiales, crearon las plantas y los animales y, tras varios intentos fallidos, formaron a los hombres de masa de maíz y sangre de danta y de serpiente. La misión de los humanos fue desde entonces, según De la Garza, venerar y nutrir a la divinidad con sangre. En este entrelazamiento de tiempos se van marcando eras y destrucciones cósmicas en las que sobresalen personajes míticos y señores sagrados, que en la narrativa dinástica aparecen vinculados con los gobernantes, especialmente en entronizaciones, anudamientos y espacios de enlace entre los seres numinosos y la comunidad de creyentes. Ayudado por invocaciones y sacrificios, que integran el cielo, la tierra y el inframundo, el sacerdote o el gobernante cuasimítico en Palenque es un demiurgo que, a través del ritual, enlaza a las deidades y a los humanos creando en la oscuridad lo que será realidad visible en la luz. Es curioso que en uno de estos relatos palencanos, en donde el poder dinástico combina las historias mítica y política, dice De la Garza, se haga referencia a la orilla del mar, un mar primordial que en la práctica, y tras los descubrimientos arqueológicos modernos, se convierte en real, dado que Palenque estuvo alguna vez a la orilla del mar, tal y como lo comprueban innumerables restos fósiles de peces, tiburones, rayas y corales descubiertos por los arqueólogos.

En su contribución, Marta Ilia Nájera Coronado aborda los "rituales calendáricos" de los "ritos ocasionales" e insiste en que no se puede confundir el tiempo mítico con el tiempo sagrado dado que este último es "por naturaleza intemporal". El tiempo mítico se refiere a los orígenes, mientras que el tiempo sagrado es ilimitado, infinito y cíclico, y rige los ritmos cósmicos de la naturaleza, la siembra, la cosecha, la lluvia o la sequía, así como la erección de grandes templos, pirámides, juegos de pelota o edificaciones, partes de ciudades articuladas con el espacio natural también sacralizado de cenotes, cuevas, ríos o lagunas. El tiempo anual y el wayeb, es decir, el período de cinco días dedicado a solemnizar el fin y el inicio de un nuevo 
ciclo, muestran el tiempo envejecido, desgastado y necesitado de un renacimiento, de modo que requiere purificaciones de los celebrantes para lograr un buen año, como privación de sal o carne, ayuno prolongado, abstinencia sexual y el ofrecimiento de sahumerios u ofrendas de sangre; o bien ritos de mayor privacidad dirigidos a aliviar algún mal que precisa de ceremonias en casas, frente al altar familiar, o en parcelas agrícolas o lugares ocultos, considerados morada de seres sobrenaturales. A ello a menudo se agregaba la ingesta ritual de cacao y de líquidos embriagantes como el balché, que propiciaba, dice Nájera, el abandono de sí mismo y la comunión más cercana con los dioses a través de oraciones, cánticos, danzas, música y, como ya se dijo, la ofrenda de la propia sangre.

Ya en la crítica a la distorsión interesada del tiempo cíclico, el arqueólogo Tomás Pérez Suárez afirma que el 21 de diciembre de 2012 fue una fecha en la que la mercadotecnia milenarista quiso ver una profecía que carece de sustento académico y ético. "Son nuestros temores", dice Pérez Suárez, "derivados del daño que hemos causado al planeta, el deterioro de las relaciones humanas y por la visión apocalíptica de las creencias religiosas judeocristianas, los que han creado estas ideas milenaristas que no tienen fundamento, y del mercantilismo salvaje del actual mundo globalizado, capaz de vender hasta nuestros miedos". Critica las páginas de internet dedicadas a publicitar el miedo postapocalíptico, que contrasta con el desdén de los medios por las numerosas investigaciones y publicaciones que demuestran la complejidad en la articulación de, por lo menos, tres sistemas calendáricos: el ritual, que es una combinación cíclica de trece números con veinte signos; el solar o agrícola, de 365 días divididos en 18 meses de 20 días y un mes más de cinco días cada 52 años, y el tercer sistema basado en la cuenta larga, que registra, al igual que los anteriores, nacimientos, alianzas matrimoniales, guerras, capturas de prisioneros y dedicación de edificios o monumentos escultóricos. Pérez Suárez analiza, entre otras inscripciones, las del sitio monumento de Tortuguero, encontrado en la cima del Cerro del Gavilán Blanco en Macuspana, Tabasco, y reportado por Frans Blom y Oliver La Farge en su Tribes and Temples de 1926. Este monumento, al cual muchos atribuyen el origen del escándalo de 2012, está fracturado en siete partes y tiene 1.90 metros de altura por 1.23 de ancho y de 12 a 13 centímetros de espesor. Tres de las partes fracturadas se encuentran en el Museo Regional Carlos Pellicer, una en el Museo Metropolitano de Nueva York, dos en colecciones particulares y de la última, que debió contener el inicio de la inscripción, se desconoce su paradero.

Michela Craveri aborda el uso del tzolkin o calendario ritual de 260 días que, según Elizabeth Hill, marca la gestación humana basada en nueve lunaciones de 29 días. Conocida por sus trabajos en los que explora el uso de la retórica, la metáfora o la paronomasia en la tradición oral y el lenguaje ritual maya, Craveri examina la operación de los mecanismos adivinatorios a partir del manejo y conocimiento de las energías de cada uno de los días del calendario por parte de los adivinos o especialistas religiosos que todavía a principios del siglo XX eran perseguidos y acusados de brujería.

Finalmente, Mario Ruz cierra el volumen con un ensayo que muestra cómo, aún muertos, los mayas permanecen en sus comunidades en una dimensión distinta, en la que los calendarios sólo importan en la medida en que los vinculan con las horas rituales de los vivos. Este salvar a los muertos del olvido incluye, por ejemplo, el solicitarles su aprobación antes de iniciar una petición de mano. Con los muertos deben tenerse en cuenta diversos animales, no solamente aves, considerados aviseros o agoreros de enfermedad y muerte, como cierto tipo de sapos, algunas clases de serpientes, gatos de monte, comadrejas que se atraviesan y "cortan" el camino, coyotes y ciervos que de pronto irrumpen en un poblado, perros y gatos que aúllan de forma lastimera, canes que "se arrastran de fundillo" hacia su amo como "midiéndole la sepultura", o mantis religiosas, mariposas, murciélagos y ríos de hormigas que entran en una vivienda y comienzan a fabricar la suya, lo que representa un mal augurio desde tiempos prehispánicos, incluso entre los nahuas. Así que, como dice uno de los informantes de Ruz: "No es así nomás, no es así nomás". El respeto ritual a los muertos 
incluye su tratamiento diferenciado según la edad, el género o la circunstancia de su deceso, de tal forma que, por ejemplo, a los bebés que murieron habiendo sido destetados debe proveérseles en su día de caldito de gallina. En las fechas especiales, los más respetuosos entre los mayas se acuestan más temprano para que los muertos puedan pasear a sus anchas por la casa. Y a pesar de que no abunda mucho en el tema, dice Ruz, existe la creencia en la reencarnación - "reemplazo", "reposición" o jelol o kelol, como se le dice entre los tojolabales - y en otras formas semejantes entre algunos pokomames, quichés y tzutuhiles, con lo que se busca mantener la continuidad de los linajes. Otro tema relevante es la resistencia de los mayas a las autopsias y su convicción de que es imposible "descansar" si no se devuelve el cuerpo completo a la tierra a la que se pertenece. Además, no se puede descansar sino hasta el noveno día, cuando el espíritu del difunto regresa a dormir a su casa como postrera despedida. Es cuando, según los achís de Rabinal, el difunto "se voltea y despierta", se percata de lo sucedido y de inmediato vuelve a entrar en un sueño, esta vez definitivo. Rezan sus novenas por razones distintas a las católicas y se pone mucho cuidado en el sepulcro y en la levantada de la sombra, o del alma, que habrá de realizarse donde haya acontecido el deceso. Ello quiere decir que, si la muerte ocurrió en Chicago, hasta allá tiene que marchar el especialista a levantar el alma. Una vez levantada ésta y pasados los nueve días, y tras celebraciones anuales o antes, durante o después de los cuarenta días o los siete años, los muertos toman sus vacaciones o se salen a dar sus vueltas. En San Pedro Soloma se les puede pedir salud, "pisto" — dinero - o amores, y para ello hay que ir a la capilla del Carwal camposanto en lunes, jueves o sábados. Los cakchiqueles que trabajan como pescadores en el lago Atitlán evitan pescar entre las once de la noche y las dos de la mañana pues, según ellos, los espíritus de los ahogados podrían atrapar las canoas. Se sabe, por ejemplo, que entre los huaxtecos se nombra padrino de muerte, y que los rituales para los muertos entre yucatecos y huaxtecos se prolongan todo el mes de noviembre. Todo forma parte del libro que no cesa de escribirse, el mundo-libro del pasado, el presente y el futuro del maya. Ruz se da tiempo para leer la naturaleza y, apoyado en el código de la memoria social, interpreta lo que de extraordinario ocurre en la cotidianidad.

Concluyo con algunas apreciaciones sobre el pesimismo cristiano y el impacto social de la industria del apocalipsis y la espectacularización del desastre a la que son tan afectos Hollywood y sus seguidores. $\mathrm{Y}$ es que, como dice Giuliano Romano, el finalismo teleológico propio del pensamiento judeocristiano es el único en el mundo fundado en la pérdida simbólica ilustrada por la expulsión del paraíso y en el castigo a la comisión del pecado. Por si no fuera suficiente lo divulgado en los medios de comunicación e internet a propósito de este profetismo comercial apocalíptico, a la fecha se estima que se han publicado alrededor de 1500 libros sobre la temática, pero muy pocos de ellos cuentan con sustento académico. Prudence Price, Nancy Farris, Anthony Aveni y otros estudiosos de la cultura maya critican la burbuja de la metafísica New Age, que creció con propósitos ideológicos y comerciales y se convirtió en una especie de Spiritual Y2K; movimiento que entusiasma a los cultistas de las técnicas de supervivencia y fomenta el interés por los fenómenos paranormales, los objetos voladores no identificados, las explosiones solares que podrían dejarnos sin energía e interrumpir las comunicaciones electrónicas, el uso de la medicina alternativa o las prácticas chamánicas -que se supone despertarán conciencias y propiciarán el advenimiento de una nueva era, eso sí, tras terribles terremotos, inundaciones o alineamientos galácticos y planetarios que invertirían los polos magnéticos del planeta Tierra y provocarían la erupción del supervolcán que se encuentra en Yellowstone, California, o el arribo del Planeta X o Nibim-.

Por su lado, en Guatemala, gran receptáculo de la civilización maya donde se combinan ignorancia, chauvinismo nacionalero y desdén por la tradición primordial, la conmemoración de 2012 hizo que el gobierno liderado por un militar, con la anuencia del conservadurismo retrógrado, decidiera utilizar la Torre del Reformador, una caricatura de la Torre Eiffel construida en 1935 durante la dictadura del general Jorge 
Ubico (1931-1944), para proyectar un video que muestra a Miguel Angel Asturias recibiendo el premio nobel de literatura en 1967, y otro que presenta a Miss Guatemala, Julieta Urrutia, quien en 1984 fue considerada una de las diez mujeres más bellas del mundo. El espectáculo, dijo el reporte oficial, también incluyó danzas mayas y la participación de artistas nacionales e internacionales. Menos publicitada, la espiritualidad popular maya se dio cita en Saq Ulew - Huehuetenango-, en Qumarkaj —Quiché-, en Iximché -Chimaltenango-, en Tikal —El Petén-, en Kaminal Juyú, en la ciudad de Guatemala, y en los sitios sagrados de Chu Saqbribal —Quiché-, Pa Sun —Chimaltenango-, Balam Abaj —Sololá-, Tzunún - Petén- y Qana Itzam y Chi Batz en Alta Verapaz.

Aunque David Stuart diga que la profecía no es tal, es evidente que, en esta movilización multicausal y en el contexto escrito registrado por los epigrafistas, queda una laguna académica significativa en torno a la aparición o el advenimiento de B'olon Yookté -B'olon Yookte' K'uh, Dios L-, un personaje poco conocido y asociado a la fecha 3114 a.C. y al final de los trece baktunes. Hace falta, además, mayor información sobre el denominado Códice 1722, conocido por Dennis y Barbara Tedlock y que, al parecer, cuenta con información similar y también diferente a la que presentan los códices de Dresde, Madrid y París, pero que ha sido prácticamente ignorado por la academia mexicana.

En la praxis humana, donde lo astronómico y lo religioso confluyen, el espacio arquitéctónico, el ritual y el ejercicio del poder están fincados en el conocimiento especializado de quienes siguen observando el amanecer, el atardecer y los espacios siderales de esa "astronomía galáctica", como la llama el arqueoastrónomo Anthony Aveni, que permitió a los mayas ubicar el centro de la galaxia y alinear sus edificios de acuerdo con el movimiento de determinados astros. En ese contexto, es mérito de la arqueología moderna, afirma el estudioso cakchiquel Lolmay Pedro García, el haber descubierto la existencia de la cuenta larga, desaparecida temporalmente hacia el final del siglo $\mathrm{X}$ y fusionada con las tradiciones del centro de
México y con el tiempo lineal de la tradición cristiana. Así, el año 2012 y el arranque del Nuevo Sol no significan una catástrofe mundial, sino una celebración espiritual que apuesta por la crítica civilizatoria, el repudio del bestialismo y el rechazo a las pulsiones que, en nombre de la ley del mas fuerte, apelan a los instintos más destructivos de los terrícolas para que, en nombre del animal que se supone todos llevamos dentro, se acepte pasivamente la estructura jerárquica que ha elitizado el mundo y corroe las bases mismas del proyecto liberal iniciado por los filósofos de la ilustración. Como dice el especialista kiché José Yac Noj, se trata de agradecer por lo que se tiene y lo que se ha recibido, de respetar todo lo que existe porque todo tiene vida, de sentir y entender que somos parte del todo y necesitamos vivir en relación equilibrada y armoniosa con ese todo, y ojalá, podríamos agregar, se trata de reencontrar una ética de convivencia social que frene y revierta la autodestrucción apocalíptica que vende con gran éxito Hollywood y está dirigida a domeñar las mentes de los menos avezados. De esa forma, puede celebrarse el inicio de un nuevo Sol, una conmemoración de gran trascendencia cósmica para los pueblos del planeta y al margen de la industria del miedo que asusta y barbariza a las muchedumbres en todas partes.

En nuestro caso, se espera que el prejuicio y el estereotipo no impidan recuperar el conocimiento ancestral con el fin de fundirlo con el saber universitario para lograr reordenar nuestras sociedades y territorios, de modo que puedan enfrentarse los retos de la mundialización del lucro y del aprovechamiento de la biodiversidad para el beneficio exclusivo de las transnacionales y las élites oligárquicas.

Los mayas y los indígenas de América siguen luchando para que sus conocimientos ancestrales reciban el reconocimiento oficial y social más allá de la turistización, la folklorización, el voyeurismo etnográfico o la experiencia estética. Ojalá que no sólo la población indígena, sino la caxlanada, la criollada y la chelonada, todos en conjunto, podamos al interior de nuestras universidades impulsar el aprendizaje y la valoración del manejo profesional de los idiomas mayas 
y la implementación curricular de cursos de etnografía que no sólo ayuden al extensionismo universitario en todas las disciplinas, sino que también empujen la transformación radical del concepto mismo de universidad monocultural y excluyente que hasta ahora padecemos. De allí que el tiempo para algunos sea el viaje; y la profecía, la instrucción para el viaje.

Dicen los sociólogos del tiempo que en este devenir de la historia local y regional se ha caminado de una sociedad regida por el tiempo del ritmo natural a una de precisión matemática y occidental, para la cual el tiempo es sinónimo de lucro, dinero y ganancia. En este caso, el tiempo de la disciplina laboral del capitalismo suprime el tiempo para el rito, el cultivo interior o el ocio creativo que asume la profecía como instrucción, y no como fuente de catastrofismo que propicia el borreguismo y la chatarrización de la cultura.

Al final, y a propósito de tantos profetismos, como dice doña Amalia Tu, una sacerdotisa maya que vende chow mein en el mercado de Tecpán, Chimaltenango, y hace pocos años participó en Kyoto, Japón, en el encendido de un gigantesco fuego ritual: "El 2012 sólo es un cambio de era en el que hay que respetar a la naturaleza para poder vivir en paz". 